\title{
Relationship of Psychosocial Factors towards Medication Adherence among Hypertension Patients in A Tertiary Hospital
}

\author{
Jalina $K^{\mathrm{a}}$, Hazwani $\mathbf{R}^{\mathrm{b}}$, Siti Zuraida $\mathrm{MR}^{\mathrm{b}}$, Nor Haty $\mathbf{H}^{\mathrm{a}}$ \\ ${ }^{a}$ Nursing Lecturer, Department of Nursing, Faculty of Medicine, UKM Medical Centre, Kuala Lumpur Malaysia \\ ${ }^{\mathrm{b}}$ Bachelor of Nursing Student, Department of Nursing, Faculty of Medicine, UKM Medical Centre, Kuala Lumpur Malaysia
}

\section{ABSTRACT}

INTRODUCTION: Hypertension is one of the invisible diseases causing heart failure and stroke, and responsible for death. This study aimed to determine the level of medication adherence and psychosocial factors among patients with hypertension, relationship between socio demographic and medication adherence, and relationship between psychosocial factors and medication adherence among patients with hypertension. MATERIALS AND METHODS: A cross-sectional descriptive study was performed at the Primary Health Clinic and Medical Clinic in one of the tertiary hospitals. There were 123 patients with hypertension who volunteered to participate using a validated adapted and modified questionnaire to assess the compliance and psychosocial factors. The data collected was analysed using IBM SPSS Statistics version 23. RESULTS: A hundred and twenty respondents were adherents to medication $(97.6 \%)$ while respondents with non-adherence to medication were $3(2.4 \%)$ with a mean adherence score of 42.2764 with $\mathrm{SD} \pm 2.67134$. Some of the psychosocial variables had good understanding, good emotional state, positive attitude, higher motivation, higher perception of severity, lower perception of susceptibility and less barrier to compliance. Emotional state was the only thing reported for the psychosocial factors as being statistically significant. The level of emotional state was found statistically significant differences with scores $\mathrm{p}=0.008$ $(p<0.05)$. CONCLUSION: The level of medication adherence was good which reflected the patients' compliance towards medication taking. This study showed a good medication adherence and compliance among hypertension patients.

KEYWORDS: medication adherence, medication compliance, psychosocial factors, hypertension.

\section{INTRODUCTION}

Hypertension is one of the chronic diseases with growing epidemic, affecting nearly one billion people in the world and poorly controlled worldwide, being the leading cause of mortality and the third largest cause of disability. ${ }^{1}$ Hypertension incidence in Asia is close to that in Western countries and it ranges from $23 \%$ to $41 \%$ among men and from $11 \%$ to $34 \%$ among women affecting all age groups. ${ }^{2}$ The World Health

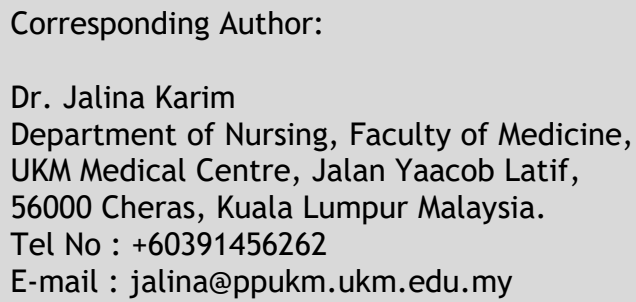

Organization (WHO) identified poor adherence as the leading cause of uncontrolled blood pressure and it was reported that $50 \%-70 \%$ of people did not take their antihypertensive medication as prescribed. ${ }^{3}$ Prevalence of hypertension among adults aged 18 years and over was $30.3 \%{ }^{4}$ and $32.6 \%$ had stopped the treatment after diagnosis.

Adherence to the treatment was depending on numerous factors such as demographic characteristics, severity of disease, complexity of drug regime (number of drugs and daily doses prescribed), drug classes (due to tolerability and side effects to medication), patient's forgetfulness, lack of understanding of the nature of the disease important for treatment, ${ }^{5}$ co-morbid medical 
conditions, cost, depression, lack of social support, poor patient-provider relationship, ${ }^{6}$ family support, selfefficacy, intention to comply, physician-patient relationship, patient satisfaction with health care provider and psychosocial factors were associated with the medication adherence. ${ }^{7}$

Accordingly, psychosocial aspects are essential in the development of hypertension. ${ }^{8}$ Furthermore, psychosocial factors related to compliance or noncompliance medication are well-recognized problems and have been documented in literature with mixed results. However, successful treatment of hypertension is important to reduce morbidity and mortality rate ${ }^{9}$ as well as in controlling health care costs. ${ }^{10}$ This study aimed to determine the level of medication adherence and psychosocial factors among patients with hypertension, relationship between socio demographic and medication adherence, and relationship between psychosocial factors and medication adherence among patients with hypertension.

\section{MATERIALS AND METHODS}

This research used a quantitative study using crosssectional descriptive design to determine the influence of psychosocial factors towards medication adherence among hypertension patients who came for follow up and sought treatment in Primary Health Clinic and Medical Clinic in one of the tertiary hospitals in the country. A convenience sampling method was used and the sample size was calculated using Raosoft Calculator. 11 The margin error was 5\%, confidence level was 95\%, estimated of population size was 915 (based on census of hypertensive patient in the Primary Health Clinic and Medical Clinic) and response distribution was 90\%. Therefore, the recommended sample size was 121 respondents. However, the total respondents involved in the study were 123. Patients with diagnosed hypertension who were on anti-hypertensive medication at least 3 months and who were on at least one type of anti-hypertensive medication were included in this study. However, pregnant mothers with diagnosed hypertension, foreign citizens and patients who were critically ill were excluded. Patients who agreed to participate were given information about the study and asked to sign consent forms. Patients were then given a set of validated adapted and modified questionnaire to complete while they were waiting to see the doctor. This questionnaire has been pre-tested in the pilot study with the Cronbach Alpha for psychosocial factor was 0.75 and for medication adherence was 0.79 .

The questionnaire used was composed of 9 demographic characteristics which were age, gender, race, body mass index (BMI), marital status, household income, level of education, disease duration and smoking. It also consisted of psychosocial factors and medication adherence. The psychosocial part consisted of 34 items in 7 psychosocial domains which were emotional state, attitude, understanding, motivation, perception of susceptibility, perception of severity and barrier to compliance. A modified version of Health Belief Model to study patients' responses to symptoms and their behaviour in response to diagnosed illness, particularly in compliance with medical regimes, were mainly used in the development of this questionnaire. The questionnaire scored used a Likert scale from 1 to 5 (never, rarely, sometimes, frequent, very frequent; very untrue, untrue, average, true, very true; extremely do not believe, do not believe, believe a little, believe, extremely believe). Total scores of the seven domains were summed up and categorized as good emotional state $(\leq 9)$ and poor emotional state $(>9)$; positive attitude $(>9)$ and negative attitude $(\leq 9)$; good understanding $(>12)$ and poor understanding $(\leq 12)$; higher motivation $(\leq 12)$ and lower motivation $(>12)$; (higher perception of susceptibility $(>9)$ and lower perception $(\leq 9)$; higher perception of severity $(>6)$ and lower perception $(\leq 6)$; less barrier $(\leq 45)$ and more barrier $(>45)$.

The medication adherence questionnaire consisted of 9 items which included drug-taking behaviour and drugstopping behaviour. Possible scores on the scale ranged from 1 to 5, with 1 indicating 'never' and 5 indicating 'very frequent'. All negatively worded scores were reversed and all scores were converted to a 0 to 100 scale. The total scores were summed up and the mean of total scores was categorised as 'compliant' if they had the score of $75 \%$ or greater, which corresponded to being compliant 'frequently' and 'very frequently' for all the items in the questionnaire. The questionnaire was in both Malay and English versions so that it would be easier for the respondents to comprehend. 


\section{RESULT}

The data was collected and analysed using IBM SPSS Statistics version 23. The normality of data was determined using the Kolmogorov-Smirnov test, as well as the skewness and kurtosis values. The significant level $(\alpha)$ was set at $p<0.05$. The levels of medication adherence among hypertension patients were presented as frequency, percentage, mean and standard deviation. The influence of psychosocial factors among hypertension patients was analysed into descriptive statistic and illustrated in frequency and percentage. Pearson Correlation Coefficient, Mann-Whitney U Test and Kruskal-Wallis Test were the tests used to determine the relationship between socio demographic data and medication adherence among hypertension patients. In order to test Pearson Correlation Coefficient, age and BMI were analysed as total scores and both variables were normally distributed. MannWhitney U Test was also used to determine relationship between psychosocial aspects and medication adherence among hypertension patients.

A total of 123 participants participated in this study making the response rate $100 \%$. Table 1 shows the demographic data of the study which consisted of age, gender, race, body mass index, marital status, household income, educational level, smoking and disease duration. The mean age of respondents was 64.39 (SD \pm 11.305 ). About $57.7 \%$ of the respondents were females while $42.3 \%$ were males. The races of respondents were mainly Malay $61.8 \%$, followed by Chinese $30.9 \%$ and Indian 7.3\%. The mean of body mass index (BMI) was 26.9821 ( $S D \pm 4.41302$ ). For household income, 56.1\% respondents had income less than RM2500; about $27.6 \%$ respondents more than RM2500, and then only $16.3 \%$ respondents had income more than RM5000. Majority of the respondents had secondary education level which was $61.8 \%$, followed by $18.7 \%$ respondents with primary education, $12.2 \%$ with diploma, $6.5 \%$ as degree holder and only $0.8 \%$ had master education. For the disease duration, respondents with 5 to 10 years that had been diagnosed with hypertension comprised most of the respondents which was $41.5 \%$.

The total score for medication adherence was 45 . (Table 1) The mean score for medication adherence was 42.2764 (SD \pm 2.67134$)$. Percentage of respondents with compliance to medication was $97.6 \%$ while respondents with non-compliance to medication were $2.4 \%$.

Table 2 shows respondents' influence of psychosocial factors among hypertension patients that consisted of 34 items and composed of 9 domains which were understanding, emotional state, attitude, motivation, perception of susceptibility, perception of severity and barrier to compliance. For the level of understanding, $96.7 \%$ of respondents had good understanding while $3.3 \%$ had poor understanding. Emotional state showed that $91.1 \%$ respondents had good level of emotional whereas $8.9 \%$ had poor level of emotional. For the level of attitude, $95.9 \%$ had positive attitude while $4.1 \%$ had negative attitude. Regarding to the level of motivation, majority of the respondents had higher motivation which was $99.2 \%$ and only $0.8 \%$ respondent had lower motivation. For the perception of susceptibility, most of the respondents had lower level of susceptibility which was $68.3 \%$ while $31.7 \%$ had higher level of susceptibility. For the perception of severity, 53.7\% respondents had higher level of severity and 46.3\% respondents had lower level of severity. For the barrier to compliance, most of the respondents were less barrier which was $99.2 \%$ and only $0.8 \%$ had more barrier to compliance.

This current study shows that there was no relationship between socio demographic data and medication adherence among hypertension patients in UKMMC as shown in Table 3.

The relationship between psychosocial factors and medication adherence among hypertension patients was summarized in Table 4. Using the Mann-Whitney U test, level of emotional state was found statistically significant differences with scores $(z=-2.644, p=0.008)$.

\section{DISCUSSION}

Overall scoring for the level of medication adherence among patients with hypertension in UKMMC was better than previous studies. Past research showed reported that only half of the respondents at Primary Health Clinic in Malaysia were adherers to medication.

5,9 However, in this current study, there was item in the medication adherence that revealed on majority of the respondents never take medication when not feeling 
Table 1: Frequency of distribution of socio demographic data of the respondents

\begin{tabular}{|c|c|c|c|c|}
\hline Variable & $\begin{array}{c}\text { Frequency } \\
\text { (n) }\end{array}$ & $\begin{array}{c}\text { Percentage } \\
(\%)\end{array}$ & $\left.\begin{array}{c}\text { Mean } \\
(\bar{x}\end{array}\right)$ & $\operatorname{SD}(\sigma)$ \\
\hline Age & & & 64.39 & 11.305 \\
\hline \multicolumn{5}{|l|}{ Gender } \\
\hline Male & 52 & 42.3 & & \\
\hline Female & 71 & 57.7 & & \\
\hline \multicolumn{5}{|l|}{ Race } \\
\hline Malay & 76 & 61.8 & & \\
\hline Chinese & 38 & 30.9 & & \\
\hline Indian & 9 & 7.3 & & \\
\hline Others & - & - & & \\
\hline Body Mass & & & 26.9821 & 4.41302 \\
\hline \multicolumn{5}{|l|}{ Index } \\
\hline \multicolumn{5}{|l|}{ Marital } \\
\hline \multicolumn{5}{|l|}{ Status } \\
\hline Single & 1 & 0.8 & & \\
\hline Married & 122 & 99.2 & & \\
\hline Divorce & - & - & & \\
\hline \multicolumn{5}{|l|}{ Monthly } \\
\hline \multicolumn{5}{|l|}{ Income } \\
\hline$<$ RM 2500 & 69 & 56.1 & & \\
\hline > RM 2500 & 34 & 27.6 & & \\
\hline > RM 5000 & 20 & 16.3 & & \\
\hline \multicolumn{5}{|l|}{$\begin{array}{l}\text { Level of } \\
\text { education }\end{array}$} \\
\hline Primary & 23 & 18.7 & & \\
\hline Level & 76 & 61.8 & & \\
\hline \multicolumn{5}{|l|}{ Secondary } \\
\hline Level & 15 & 12.2 & & \\
\hline Diploma & 8 & 6.5 & & \\
\hline Level & 1 & 0.8 & & \\
\hline Degree Level & - & - & & \\
\hline \multicolumn{5}{|l|}{ Master Level } \\
\hline \multicolumn{5}{|l|}{ PhD Level } \\
\hline \multicolumn{5}{|l|}{ Disease } \\
\hline \multicolumn{5}{|l|}{ Duration } \\
\hline$\leq 4$ & 20 & 16.3 & & \\
\hline $5-10$ & 51 & 41.5 & & \\
\hline $11-15$ & 24 & 19.5 & & \\
\hline$>15$ & 28 & 22.8 & & \\
\hline \multicolumn{5}{|l|}{ Smoking } \\
\hline Yes & 9 & 7.3 & & \\
\hline No & 114 & 92.7 & & \\
\hline $\begin{array}{l}\text { Level of } \\
\text { medication } \\
\text { adherence } \\
\text { among } \\
\text { hypertension } \\
\text { patients. }\end{array}$ & & & 42.2764 & 2.67134 \\
\hline Compliance & 120 & 97.6 & & \\
\hline $\begin{array}{l}\text { Non- } \\
\text { compliance }\end{array}$ & 3 & 2.4 & & \\
\hline
\end{tabular}

well and never felt difficult to take medication every day. In addition, respondents often neglected to take antihypertensive medicine and they admitted that if they failed to take it, they would never take a double dose of medication. Similarly, previous studies found that the lack of dosage was largely due to the forgetfulness of patients and they often failed to take their medicine. 5,9 Most patients in the study setting had good understanding, good emotional state, positive attitude, higher motivation, higher perception of severity, lower IMJM Volume 20 No.2, Apr 2021

perception of susceptibility and less barriers to compliance. According to Hasan and team, perception of susceptibility assessed patient's perception of possible cause of hypertension and perception of severity addressed patient's perception that their medication would interact adversely with traditional medicine they were taking or with food. ${ }^{7}$ Attitudes of individuals can play a critical role in blood pressure control and liking to take medication is the reason for adherence in United States. ${ }^{13}$ Understanding beliefs about illness, medication and self-efficacy is critical to better achieving optimal medication adherence and hypertension management. ${ }^{14}$

Table 2: Influence of psychosocial factors towards medication adherence

\begin{tabular}{|c|c|c|}
\hline Variables & Frequency (n) & Percentage $(\%)$ \\
\hline \multicolumn{3}{|l|}{ Understanding } \\
\hline Poor & 4 & 3.3 \\
\hline Good & 119 & 96.7 \\
\hline \multicolumn{3}{|l|}{ Emotional State } \\
\hline Poor & 11 & 8.9 \\
\hline Good & 112 & 91.1 \\
\hline \multicolumn{3}{|l|}{ Attitude } \\
\hline Negative & 5 & 4.1 \\
\hline Positive & 118 & 95.9 \\
\hline \multicolumn{3}{|l|}{ Motivation } \\
\hline Lower & 1 & 0.8 \\
\hline Higher & 122 & 99.2 \\
\hline \multicolumn{3}{|c|}{ Perception of Susceptibility } \\
\hline Lower & 84 & 68.3 \\
\hline Higher & 39 & 31.7 \\
\hline \multicolumn{3}{|l|}{ Perception of Severity } \\
\hline Lower & 57 & 46.3 \\
\hline Higher & 66 & 53.7 \\
\hline \multicolumn{3}{|l|}{ Barrier to Compliance } \\
\hline Less & 122 & 99.2 \\
\hline More & 1 & 0.8 \\
\hline
\end{tabular}

Social support helps patients in reducing negative perspectives to treatment, having motivation and remembering to implement the treatment as well. ${ }^{15}$

In this study, there was no relationship between socio demographic data and medication adherence among hypertension patients. Previous study also mentioned that adherence to prescribed medications was not moderated by gender and level of education ${ }^{16}$ but those with less income, were less likely to adhere to medication. ${ }^{17}$ This was a contra with the previous study done which showed that patients from Malay and Chinese ethnic groups were also more likely to adhere 
Table 3: Relationship between Sociodemographic data and Medication Adherence among Hypertension Patients

\begin{tabular}{|c|c|c|c|c|c|}
\hline & $\overline{\mathrm{Med}}$ & $\overline{\mathrm{n} \mathrm{Ad}}$ & e among $\mathrm{Hy}$ & ion Patien & \\
\hline & & $\mathrm{N}$ & Mean Rank & $x^{2}$ & p-value \\
\hline *Marital Status & Single & 1 & 114.5 & 2.282 & 0.131 \\
\hline & Married & 122 & 61.57 & & \\
\hline & Divorce & - & - & & \\
\hline Race & Malay & 76 & 62.22 & 1.119 & 0.549 \\
\hline & Chinese & 38 & 64.34 & & \\
\hline & Indian & 9 & 50.22 & & \\
\hline & Others & - & - & & \\
\hline Household & $<$ RM 2500 & 69 & 59.98 & 2.267 & 0.322 \\
\hline & $>$ RM 2500 & 34 & 59.78 & & \\
\hline & > RM 5000 & 20 & 72.75 & & \\
\hline Level of education & Primary Level & 23 & 71.43 & 3.275 & 0.513 \\
\hline & Secondary Level & 76 & 57.69 & & \\
\hline & Diploma Level & 15 & 66.53 & & \\
\hline & Degree Level & 8 & 66.19 & & \\
\hline & Master Level & 1 & 71.00 & & \\
\hline & PhD Level & - & & & \\
\hline Disease Duration & $\leq 4$ & & 20 & 4.123 & 0.249 \\
\hline & $5-10$ & & 51 & & \\
\hline & $11-15$ & & 24 & & \\
\hline & $>15$ & & 28 & & \\
\hline & & & & U-value & \\
\hline **Gender & Male & 52 & 62.51 & 1819.500 & 0.890 \\
\hline & Female & 71 & 61.63 & & \\
\hline Smoking & Yes & 9 & 44.44 & 364.000 & 0.139 \\
\hline & No & 114 & 63.32 & & \\
\hline
\end{tabular}

compared to patients from Indian subgroups. ${ }^{5}$ Good adherence to antihypertensive agents was more common among the patients who had used antihypertensive agents for more than ten years. ${ }^{18}$ Previous studies also showed that older age was more adhere to medication compared to young age. ${ }^{19}$ However, it was found that there was no relationship in this current study.

All the psychosocial factors had no statistically significant relationship with the level of medication adherence among hypertension patients in UKMMC except for the emotional state. Emotional state was the only one identified as the psychosocial factor that affected the level of medication adherence. According to Hassan et al., Emotional state can be measured by depression, anxiety and stress. 7 However, in the previous study, emotional was classified as a depression and had recently been added to the list of factors associated with non-adherence to antihypertensive medication which demonstrated a significant association between depression, as a multivariate factor and nonadherence. 20 High stress was associated with medication non-adherence among hypertensive patients from primary health clinics. ${ }^{21}$ Patients who displayed high knowledge of the medical regimen, higher satisfaction with medical care, positive family member social support, and stronger coping behaviour were significantly more likely to have high levels of adherence. $^{22}$ Furthermore, patients with better awareness were more likely to adhere to their treatment. $^{23}$

\section{CONCLUSION}

In conclusion, emotional state was the only one identified as a psychosocial factor that affected the level of medication adherence. Thus, the patients' compliance towards hypertension treatment is very important in the management of hypertension patients. Long-term observation, health education and advancement of technologies which is using applications on smartphones should be provided to increase the rate of compliance by improving patient's knowledge and perceptions about hypertension and its consequences. 
Table 4: Relationship between Psychosocial Factors and Medication Adherence Among Hypertension Patients

\begin{tabular}{|c|c|c|c|c|}
\hline \multirow[t]{2}{*}{ Variables } & \multicolumn{4}{|c|}{$\begin{array}{l}\text { Medication Adherence among } \\
\text { Hypertension patients }\end{array}$} \\
\hline & $\mathrm{N}$ & $\begin{array}{l}\text { Mean } \\
\text { Rank }\end{array}$ & $\mathrm{H}$ & $\mathrm{p}$-value \\
\hline $\begin{array}{l}\text { Emotional State } \\
\text { Poor } \\
\text { Good }\end{array}$ & $\begin{array}{c}11 \\
112\end{array}$ & $\begin{array}{l}35.45 \\
64.61\end{array}$ & 324.000 & 0.008 \\
\hline $\begin{array}{l}\text { Attitude } \\
\text { Negative } \\
\text { Positive }\end{array}$ & $\begin{array}{c}5 \\
118\end{array}$ & $\begin{array}{l}50.80 \\
62.47\end{array}$ & 239.000 & 0.464 \\
\hline $\begin{array}{l}\text { Understanding } \\
\text { Poor } \\
\text { Good }\end{array}$ & $\begin{array}{c}4 \\
119\end{array}$ & $\begin{array}{l}88.38 \\
61.11\end{array}$ & 132.500 & 0.124 \\
\hline $\begin{array}{c}\text { Motivation } \\
\text { Lower } \\
\text { Higher }\end{array}$ & $\begin{array}{c}1 \\
122\end{array}$ & $\begin{array}{l}19.50 \\
62.35\end{array}$ & 18.500 & 0.221 \\
\hline $\begin{array}{l}\text { Perception of } \\
\text { Susceptibility } \\
\text { Lower } \\
\text { Higher }\end{array}$ & $\begin{array}{l}84 \\
39\end{array}$ & $\begin{array}{l}59.70 \\
66.96\end{array}$ & 1444.500 & 0.283 \\
\hline $\begin{array}{l}\text { Perception of } \\
\text { Severity } \\
\text { Lower } \\
\text { Higher }\end{array}$ & $\begin{array}{l}57 \\
66\end{array}$ & $\begin{array}{l}64.24 \\
60.07\end{array}$ & 1753.500 & 0.509 \\
\hline $\begin{array}{l}\text { Barrier to } \\
\text { Compliance } \\
\text { Less } \\
\text { More }\end{array}$ & $\begin{array}{c}122 \\
1\end{array}$ & $\begin{array}{c}62.46 \\
6.00\end{array}$ & 5.000 & 0.107 \\
\hline
\end{tabular}

\section{AUTHOR CONTRIBUTION}

All authors shared equal effort contribution towards: (1) substantial contributions to conception and design, acquisition, analysis and interpretation of data; (2) drafting the article and revising it critically for important intellectual content; and (3) final approval of the manuscript version to be published.

\section{FUNDING}

This paper is the product of research sponsored by Faculty of Medicine, Universiti Kebangsaan Malaysia through a research number FF-2017-084.

\section{ETHICAL APPROVAL}

Ethical approval from the Ethics Committee of Universiti Kebangsaan Malaysia (UKM) was obtained. Permission to conduct the study in follow-up clinic was obtained from the Head of Department of Family Medicine and the Head of Department of Medicine. Each participant was adequately informed about the IMJM Volume 20 No.2, Apr 2021 purpose, method, anticipated benefit and risk of the study by the data collectors. Written consent was obtained from study participants and anonymity was maintained to ensure confidentiality.

\section{REFERENCES}

1. Chrostowska M, Narkiewiez K. Improving patient compliance with hypertension treatment: mission possible? Current vascular pharmacology. Curr Vasc Pharmacol. 2010;8(6):804-7.

2. Abdul Rahman AR, Wong J-G, Kwong GMY, Morales DD, Sritara P, Sukmawan R, et al. Perception of Hypertension Management by Patients and Doctorsin Asia: Potential to Improve Blood Pressure Control. Asia Pasific Fam Med. 2015;14(1):2.

3. Hashimi S., Afridi M., Abbas K, Sajwani R., Saleheen D, Frossard P., et al. Factors Associated with Adherence to Anti hypertensive Treatment in Pakistan. PLoS One. 2007;2(3):280.

4. Institute for Public Health. National health Morbidity Report. Instituite for Public Health, Ministry of Health Malaysia. 2015.

5. Ramli A, Ahmad NS, Paraidathathu T. Medication adherence among hypertensive patients of primary health clinics in Malaysia. Patient Prefer Adherence. 2012;6:613-22.

6. Hashmi SK, Afridi MB, Abbas K, Sajwani RA, Saleheen D, Frossard PM, et al. Factors associated with adherence to anti-hypertensive treatment in Pakistan. PLoS One. 2007;2(3).

7. Hassan NB, Hasanah CI, Foong K, Naing L, Awang R, Ismail SB, et al. Identification of psychosocial factors of noncompliance in hypertensive patients. J Hum Hypertens. 2006;20 (1):23-9.

8. Cuffee Y, Ogedegbe C, Facep MPH, Williams NJ. Psychosocial risk factors for hypertension: an update of the literature. Curr Hypertens Rep. 2015;16(10):1-18.

9. Ismael Z, Majeed A, Jobori SS Al, A HA. Original paper Compliance of Hypertensive Patients to Medication in AL-Imam AL-Hussein medical City - Kerbala- 2018. 2018;11(2):4048-58.

10. Hughes MC. Improving medication adherence. Nurs Made Incred Easy. 2012;10(6):56.

11. Raosoft Calculator [Internet]. 2004 [cited 2016 
Dec 28]. Available from: www.raosoft.com/ samplesize.html

12. Turki A., Sulaiman SA. Elevated Blood Pressure Among Patients With Hypertension in general Hospital in Penang Malaysia. Int J Pharm Pharm Sci. 2010;2(1):24-32.

13. Egan BM, Lackland DT, Cutler NE. Awareness, Knowledge, and Attitudes of Older Americans About High Blood Pressure. JAMA Intern Med. 2003;163(6):681-7.

14. Al-Noumani H. Health beliefs and Anti Hypertensive Medication Adherence in Oman. University of North Carolina; 2016.

15. Jin J, Sklar GE, Min V, Oh S. Factors affecting therapeutic compliance: A review from the patient 's perspective. Ther Clin Risk Manag. 2008;4
(1):269-86.

16. Andrea MG. HypAndrea, M. G. 2013. Hypertension Knowledge, Expectation of care, Social Support and Adherence to prescribed medications of African Americans with hypertension. Public Health Journal,.ertension Knowledge, Expectation of care, Social Support and Adherenc. Public Heal J. 2013;

17. Murphy A, Jakab M, McKee M, Richardson E. Persistent low adherence to hypertension treatment in Kyrgyzstan: How can we understand the role of drug affordability? Health Policy Plan. 2016;31(10):1384-90.

18. Lee GKY, Wang HHX, Liu KQL, Cheung Y, Morisky DE, Wong MCS. Determinants of Medication Adherence to Antihypertensive Medications among a Chinese Population Using Morisky Medication Adherence Scale. PLoS One. 2013;8(4).

19. Juste M. Medication adherence. Pharm Hosp Clin. 2019;54(2):107-8.

20. Wang PS, Bohn RL, Knight E, Glynn RJ, Mogun $\mathrm{H}$, Avorn J. Non Compliance with Antihypertensive Medications The Impact of Depressive Symptoms and Psychosocial Factors. J Gen Intern Med. 2002;17(7):504-11.

21. Crowley MJ, Grubber JM, Olsen MK, Bosworth HB. Factors associated with non-adherence to three hypertension self-management behaviors: Preliminary data for a new instrument. J Gen Intern Med. 2013;28(1):99-106.
22. Morisky DE, Ang A, Krousel-Wood M, Ward HJ. Predictive validity of a medication measure in an outpatient setting. J Clin Hypertens. 2008;5(10):348 -54 .

23. Ambaw AD, Alemie GA, W/Yohannes SM, Mengesha ZB. Adherence to antihypertensive treatment and associated factors among patients on follow up at University of Gondar Hospital, Northwest Ethiopia. BMC Public Health. 2012;12 (1):282. 